\title{
SETTING SPEED LIMITS IN INTERURBAN SINGLE-CARRIAGEWAY HIGHWAYS USING EXPERT'S JUDGMENT
}

\author{
Ana Bastos Silva, Álvaro Seco, Nuno Gregório \\ CITTA - Research Centre for Territory, Transports and Environment, Portugal
}

Submitted 7 July 2015; resubmitted 27 September 2015, 23 December 2015; accepted 5 February 2016

\begin{abstract}
Until recently, the design of road infrastructure involved mainly concerns related to the base speed value and to requirements ensuring a high level of service. Currently, it is widely accepted that only an integrated approach is able to take into account the interests and needs of all the involved stakeholders, namely the need of traffic fluidity by motor vehicles, and quality of life and safety associated to other users and local residents. This vision has been leading to different speed management approaches, particularly in relation to the setting of the appropriate and coherent speed limits along extensive routes. In this context, this study is part of a broader research program aimed to develop a methodology of speed management with a widespread use applied to single carriageway roads in interurban areas, crossing different road surrounding environments with varying rural, urban or mixed characteristics. More specifically, this research line is focused on the development of a decision-support methodology for the definition of the appropriate speed limit, based on the drivers' willingness to naturally accept successive changes in the speed limits in successive stretches of the roads. This decision-making process necessarily involves a broad set of variables and factors that might be divided in two fundamental components: (1) road geometry, and (2) interaction between the road and its surrounding environment. The effect related to the geometric characteristics has already been extensively studied, thus, this paper is focused on speed limit modelling having exclusively into account the latter component, leaving geometryrelated considerations to the final decision-making process. A MultiNomial Logit (MNL) discrete choice model was developed. The modelling work was carried out using a case study involving $55.4 \mathrm{~km}$ and $11 \mathrm{~km}$ more, for validation purposes - of rural roads crossing different environments. The model was estimated based on the judgments of fourtraffic safety experts applied to each direction of each road stretch (200 m long). Before the modelling development, a factor analysis involving the whole set of variables was carried out, in order to detect not directly observable common features on its structure that may influence the final outcome of model estimation. This analysis allowed to corroborate the overall variable selection process. The developed model adjusts quite well to the data with McFadden pseudo- $R^{2}$ of 0.447 . Without loss of explaining power it was possible to avoid the presence of subjectivity related to a qualitative evaluation of some explanatory variables, greatly enhancing the model's robustness and transferability to other locations and countries. The new modelling structure also facilitates the interpretation of the validation results and enables the models to be developed to represent different levels of safety related sensitivity existent amongst the expert community, by using a 'conservative expert' evaluation. The results validation has showed the models to be robust and useful as decision support tools applied to speed limits' evaluation processes.
\end{abstract}

Keywords: speed limits; rural highways; expert's judgment; multinomial logit; factor analysis.

\section{Introduction}

The development of a robust methodology for setting speed limits has been in recent years the object of a number of research studies, resulting in the development of different approaches (Agent et al.1998; Austroads 2005, 2009; Elvik 2002) based in different conceptual principles and legal frameworks. In fact, up until the 80s, rural highways technical recommendations based the definition of geometrical and functional solutions on operational concerns without major consideration for the highways integration on the surrounding environment (Neuman et al. 2002). National and regional road networks were thus planned and designed to provide uninterrupted flow conditions that provide a high level of service.

Notable examples of this approach are the methodologies related with the engineering philosophy, whose techniques are usually based on the 85th percentile of speed $\left(V_{85}\right)$. This value is regarded as corresponding to a minimum accident risk for the driver (DfT 2013). How-

Corresponding author: Ana Bastos Silva

E-mail: abastos@dec.uc.pt 
ever, despite their importance, methodologies based on this parameter have been criticized because: it assumes that drivers always select their travel speed taking adequate and objective consideration of road safety issues; it is considered to be the cause of a gradual increase of the average operating speed; it generates an inadequate measure of speed consistency; it tends to be less effective, the more residential the surrounding environment is; and it cannot be considered as objectively rational, since it considers an erroneous driver perception of speed impacts (Elvik 2010; Park, Saccomanno 2006; TRB 1998).

Despite the undoubtable relevance of geometric features on speed limit setting process, these approaches have increasingly been considered as incomplete and insufficient. In fact, the setting and growth of ever more urban developments in the roads' vicinities has, in many countries, led to the existence of not only pure rural environments, but also disperse and consolidated built-up areas in their surroundings, with the boundaries between them very often difficult for road planners and designers to properly identify them and to act accordingly. This has tended to result in ever more frequent occurrence of complex road environments, where the traditional road design and management principles, as well as speed limits setting approaches, tended not to be appropriate, resulting in many cases in significant and severe speed related accidents (Aarts, Van Schagen 2006; Hauer 2009; Stuster et al. 1998; TRB 1998).

New, speed control based, rural highways and networks' design and management approaches were then developed, namely using physical devices for traffic calming purposes (Hallmark et al. 2008). These, in many countries and in many states within the US, resulted in the adoption of across the board low speed limits with somehow controversial results, namely the implementation of too restrictive road operation conditions (Farmer et al. 1999; Kockelman 2006; Lave, Elias 1994; Malyshkina, Mannering 2008).

By then, in some European countries, but also in the US, Canada and Australia, an approach based on the application of speed limits in accordance with drivers' natural expectancies, and on the design of self-explainable roads, started to emerge (Mackey 2004; Neuman et al. 2002; Stamatiadis 2001). This kind of approach assumed the setting of speed limits compatible with local typical driving practice, based essentially on the observed 85th speed percentile and on the road speed design (Donnell et al. 2009).

Currently, it is consensually accepted that a more integrated approach is needed, in order to, coherently, taking into consideration the interests and needs of the different road users and stakeholders (Austroads 2005; DfT 2013). The integrated consideration of problems other than those related only to the uninterrupted and safe flow of traffic, was in fact the base for the development of innovative speed management principles and solutions in several countries, such as: 'Ville plus sûre, quartiers sans accidents' in France, 'Environmentally adapted through roads' in Denmark, 'Village speed con- trol working group' in the UK, and 'Environmental adaptation of the main street in rural towns' in Australia (Mackey 2004; TRB 2011).

By 2000 new speed limits setting methodological approaches emerged, supported by new design models and tools, and taking into consideration roads' geometric, safety and operational factors. The Australian XLIMITS family of applications, later adapted for the US and New Zealand, are good examples of this kind of approach (Austroads 2005). They enable the selection of speed limits by taking into consideration a wide range of explanatory variables, descriptive of the infrastructure, land use, local safety and operational characteristics (Austroads 2005; Srinivasan et al. 2006). However, despite being well adapted to the standard road environments of the countries where they were developed, these models tend to require the availability of a wide range of data, which is not always possible. That is the case of local accident or speed geographical distribution data, which tends to be difficult and, due to economic constrains, many times impossible to obtain.

This research work is part of a broader research program aiming to set speed limits along an itinerary, and which will take into consideration three main levels: shorter stretches, longer stretches, and along the itinerary. This paper is focused on the first stage of the work and aims to define a speed limit prediction model having only into account characteristics related to road functionality and environment. This research program is based on the assumption that road geometric characteristics, despite being extremely relevant in the decision-making process, shall be addressed in a second stage, applied to longer stretches than those now under study, which are considered to be too short to correctly explore geometric features. In this phase, besides geometric features, concerns related to homogeneity and speed consistency - according to Park and Saccomanno (2006), it corresponds to the difference between speeds in two successive elements of a given road section must also be included in the analysis, assuring the drivers' willingness to naturally accept successive changes in the speed limits in successive road stretches. Unlike the effect of the surrounding environment over speed, which is field that has not yet been properly addressed, the relationship between geometric characteristics and the operating speed has been addressed by the scientific community in several studies, such as Dell'Acqua, Russo (2011), Dell'Acqua (2015) and Russo et al. (2015). Therefore, this paper aimed to deliver an accessible and easy to use by the technical community methodology, based on data which can be collected remotely and is easily measurable. A different approach is considered, which emphasizes factors related with the prevailing road environment, especially focusing on road integration into the surrounding areas, which is a field that has not yet been properly addressed. Nevertheless, for each stretch of road, the most restrictive speed limit value from those independently established in each phase of analysis will always prevail, for the sake of safety. 
Previous work had already been done directed at the identification of a robust methodological approach (Seco et al. 2008; Correia, Bastos Silva 2010). As other studies focused on road environment classification (Dell'Acqua et al. 2011), this research work is based on expert judgement. Additional development was still justified with the present paper dealing with the following two main areas: (1) Selection of a complete set of objective and easily measurable explanatory variables to be used in speed limit setting models; (2) Development of models based more on experts' 'conservative' evaluations, instead of on 'average' experts' evaluations. This work, which has used a more extensive calibrating data set, has produced significant developments which resulted in models with improved prediction capabilities, objectivity and applicability in different environments.

The modelling work was carried out using MultiNomial Logit (MNL) techniques, which are adequate to model discrete choice problems (Correia, Bastos Silva 2011). The final model has shown an McFadden pseudo- $R^{2}$ of 0.447 in the calibration process, which, as it is known, corresponds to a standard multiple regression $R^{2}$ of approximately 0.8 , and was also subjected to a successful validation process using an independent data set collected from an $11 \mathrm{~km}$ itinerary.

\section{Methodological Approach}

\subsection{Global Approach}

The present research takes advantage of previous works' results (Correia, Bastos Silva 2011; Seco et al. 2008), which have shown the adequacy of using experts' judgment, i.e. speed limit setting involving the use of a model based on expert assessment on a number of road stretches, to estimate adequate speed limits along those successive stretches of roads, which were then 'explained' by applying MNL techniques to develop models based on sets of explanatory variables representing different layout and surrounding environment characteristics.

However, additional development was still justified with the present paper dealing with main issues:

- selection of a complete and, eventually extended, set of objective and easily measurable explanatory variables (namely recurring to remote sources, like aerial and satellite imagery) to be used in the models, without them losing their explanatory capabilities; specific attention was given to the identification of objectively quantifiable variables, representing the level of roads' lateral restrictions (including buildings or others obstacles situated in the roadside and that might limit drivers' vision and, thus, will tend to influence their behaviour and speed choice), which have previously proved to be of significant importance;

- performing a factor analysis to detect not directly observable common features and describe variability among observed, correlated variables in terms of a potentially lower number of unobserved variables (called factors);
- development of models based more on 'conservative' experts' evaluations, instead of on 'average' experts' evaluations (see 1.4), enabling the models to be developed to address more or less stringent safety concerns, while at the same time making the models results more stable by reducing the impact resulting from the topical lack of consensus between experts, and thus becoming easier to validate.

In order to increase the robustness of the new models, two new rural highways' itineraries were also studied resulting in a data set collected from 4 different itineraries, all of which two lane single carriageway rural roads, totalling $55.4 \mathrm{~km}$. A different $11 \mathrm{~km}$ itinerary was later used for the models' validation process. Apart from the basic common geometrical and functional characteristics (single lane carriageway, two way direction, national or regional roads), these itineraries present a significant intra and inter variability both in terms of specific layout solutions (e.g. (in)existence of intersections, or of real life actuated speed control traffic signals, or of raised median curbs), and of surrounding environments' characteristics (pure rural, urban and mixed zones).

Each one of the itineraries was sub-divided in $200 \mathrm{~m}$ stretches of road, which proved a sufficiently short dimension to guaranty homogeneous roads' physical and surroundings' characteristics, while at the same time being long enough to enable the experts to make stable assessments.

In order to guaranty a systematic but simple analysis, it was assumed that all road stretches would be classified, by the experts, in one of three possible types, depending on the characteristics of the surrounding environment: 'Rural zone', characterized for having none or only negligible urban type activities, where $90 \mathrm{~km} / \mathrm{h}$ maximum legal speed (the Portuguese speed limit for this kind of road and environment) were to be set; 'mixed zone', characterized for having disperse urban occupancy located at some distance from the road, where the selected speed limit would be $70 \mathrm{~km} / \mathrm{h}$; 'urban zone', characterized for having significant surrounding urban occupancy leading to a significant presence of functions other than those related to the motorized traffic through movements (e.g. pedestrian presence and crossing activities, direct accesses to the adjacent buildings and properties, eventually on road parking), where the selected speed limit would be $50 \mathrm{~km} / \mathrm{h}$, the international reference value for urban environments.

Based on this set of simple rules to select adequate speed limits, 4 experts were asked to, independently and based on their expertise, select the most appropriate speed limit for each stretch, while driving in normal traffic conditions along the different itineraries. These experts were road traffic professors, aged between 40-55 years old, with an extensive experience in road design and safety. Further, it was asked from them that their evaluation should only be influenced by the roads' functionalities and their interactions with the surrounding environment, thus disregarding specific design alignments such as sinuosity or grades. 
In parallel, in order to classify each stretch of road in accordance with the selected potential explanatory variables, an independent team has performed an on-site detailed objective characterization of them in relation to a number of characteristics. This process was afterwards complemented by another data gathering process based on observation of Google Maps images.

The data obtained by both processes was then introduced in a database, with the SPSS statistical software being selected to perform the development of the MNL models.

\subsection{Objective vs Subjective Explanatory Variables}

Previous work (Correia, Bastos Silva 2011; Seco et al. 2008) has shown that roads' lateral restriction and surrounding environment characteristics are extremely relevant in defining their adequate speed limits, with binary variables representing the results of systematic, although subjective observers' evaluations of these characteristics, showing the most significant statistical significance as explanatory variables of the relevant MNL models.

However, the inherent subjectivity associated with these variables represent a real life potential problem since it makes the models less easily transferable to different locations or countries, other than the ones for which they were developed, because these locations cannot be characterized in an absolutely similar way. Further, this reduces the potential these models might offer to applications where different land use planning options are to be confronted with their impacts over roads' operation conditions, namely acceptable operation speeds.

In the current model approach, the surrounding characteristics and influence over the roads' operation was assumed to be representable by a specific combination of some or all of three objective, analytically describable, explanatory variables: ED - Edification Density [number of buildings/100 m]; MD - Minimum Distance to the road of the nearest building along the stretch of road [m]; MED - Median of Distances of all the buildings located on the stretch of road $[\mathrm{m}]$, which in the current case was considered as an adequate measure of central tendency of this variable. Based on some exploratory work, it was also considered that only buildings located less than $30 \mathrm{~m}$ away from the roads were relevant. All these variables were quantified for each stretch of road using available local aerial photography and Google Maps images.

\subsection{Selected Variables}

The potential explanatory variables, which were tested are presented in Tables 1 and 2. They were selected taking into consideration other reference works (Austroads 2005; Cruzado, Donnell 2010; DfT 2013; Fitzpatrick et al. 2001; Greibe et al. 1999; TRB 1998), as well as the experts' suggestions. Special attention was given to the selection of variables with the potential to represent the conditioning effect presented by the roads' surrounding environment.
Table 1. Discrete and binary explanatory variables

\begin{tabular}{|c|c|c|c|c|}
\hline No & Name & Desc & Type & $\begin{array}{c}\text { Mode } \\
\text { (relative } \\
\text { frequency) }\end{array}$ \\
\hline 1 & INTERR & $\begin{array}{l}\text { Intersections at the } \\
\text { nearside (NS) }\end{array}$ & discrete & $0(73.4 \%)$ \\
\hline 2 & INTERL & $\begin{array}{l}\text { Intersections at the } \\
\text { offside (OS) }\end{array}$ & discrete & $0(73.3 \%)$ \\
\hline 3 & GAR & $\begin{array}{l}\text { Off-road individual } \\
\text { parking accesses at the } \\
\text { NS }\end{array}$ & discrete & $0(8$ \\
\hline 4 & GARAGL & $\begin{array}{l}\text { Off-road individual } \\
\text { parking accesses at the } \\
\text { OS }\end{array}$ & discrete & $0(8$ \\
\hline 5 & NATERR & $\begin{array}{l}\text { Motorizec } \\
\text { accesses a }\end{array}$ & discrete & $0(58.5 \%)$ \\
\hline 6 & NATERL & $\begin{array}{l}\text { Motorized traffic lateral } \\
\text { accesses at the OS }\end{array}$ & discrete & $0(58.4 \%)$ \\
\hline 7 & NAPARR & $\begin{array}{l}\text { On-road parking } \\
\text { spaces at the NS }\end{array}$ & discrete & $0(91.2 \%)$ \\
\hline 8 & NAPARL & spaces at the & discrete & $0(91.2 \%)$ \\
\hline 9 & NAPEDR & accesses at the NS & discrete & $0(81.8 \%)$ \\
\hline 10 & NAPEDL & $\begin{array}{l}\text { Pedestrian paths' } \\
\text { accesses at the OS }\end{array}$ & discrete & $0(81.8 \%)$ \\
\hline 11 & NAPEHR & $\begin{array}{l}\text { Buildings' pedestr } \\
\text { accesses at the NS }\end{array}$ & discrete & $0(86.6 \%)$ \\
\hline 12 & NAPEHL & accesses at th & discrete & $0(86.6 \%)$ \\
\hline 13 & NBUSR & Bus stop at the NS & discrete & $0(89.9 \%)$ \\
\hline 14 & NBUSL & Bus stop at the OS & discrete & $0(89.9 \%)$ \\
\hline 15 & NCRO & $\begin{array}{l}\text { Formal pedestrian } \\
\text { crossings }\end{array}$ & discrete & $0(89.3 \%)$ \\
\hline 16 & NGASR & Filling station at the & discrete & $0(95.6 \%)$ \\
\hline 17 & NGASL & Filling station at the OS & discrete & $0(95.6 \%)$ \\
\hline 18 & SIGNR & $\begin{array}{l}\text { Speed control traffic } \\
\text { lights at the NS }\end{array}$ & discrete & $0(92.9 \%)$ \\
\hline 19 & SIGNL & $\begin{array}{l}\text { Speed } \\
\text { lights a }\end{array}$ & discrete & $0(92.9 \%)$ \\
\hline 20 & SIDEWR & Sidewalks at the NS & binary & $0(93.2 \%)$ \\
\hline 21 & SIDEWL & Sidewalks at the OS & binary & $0(93.3 \%)$ \\
\hline 22 & ISLAND & Central Island & binary & $0(87.3 \%)$ \\
\hline 23 & AVCOR & $\begin{array}{l}\text { Medium level of lateral } \\
\text { restrictions at the NS }\end{array}$ & binary & $0(75.3 \%)$ \\
\hline 24 & AVCOL & $\begin{array}{l}\text { Medium level of lateral } \\
\text { restrictions at the OS }\end{array}$ & binary & $0(76.4 \%)$ \\
\hline 25 & HICOR & $\begin{array}{l}\text { High level of lateral } \\
\text { restrictions at the NS }\end{array}$ & binary & $0(89.2 \%)$ \\
\hline 26 & HICOL & $\begin{array}{l}\text { High level of lateral } \\
\text { restrictions at the OS }\end{array}$ & binary & $0(89.9 \%)$ \\
\hline
\end{tabular}

Note: The names of the variables in the model use the $\mathrm{R}$ and L letters to differentiate nearside (Right) and offside of the road (Left). Portugal is a country with right-hand traffic. 
Table 2. Continuous variables

\begin{tabular}{|c|c|c|c|c|c|c|}
\hline No & Name & Description & Type & Mean & Min & $\operatorname{Max}$ \\
\hline 27 & EDR & Edification density at the NS [number of buildings $/ 100 \mathrm{~m}$ ] & continuous & 1.02 & 0.00 & 9.50 \\
\hline 28 & EDL & Edification density at the OS [number of buildings $/ 100 \mathrm{~m}$ ] & continuous & 1.02 & 0.00 & 9.50 \\
\hline 29 & MDR & Minimum distance between edifications and carriageway at the NS [m] & continuous & 20.46 & 1.50 & 30.00 \\
\hline 30 & MDL & Minimum distance between edifications and carriageway at the OS $[\mathrm{m}]$ & continuous & 20.46 & 1.50 & 30.00 \\
\hline 31 & MEDR & Median distance between edifications and carriageway at the NS [m] & continuous & 22.96 & 1.50 & 30.00 \\
\hline 32 & MEDL & Median distance between edifications and carriageway at the OS [m] & continuous & 22.96 & 1.50 & 30.00 \\
\hline
\end{tabular}

Note: The names of the variables in the model use the R and L letters to differentiate nearside (Right) and offside of the road (Left). Portugal is a country with right-hand traffic.

Most variables are of a discrete type. Exceptions to this rule are the SIDEW ones and the subjective variables representing the existing lateral restrictions which are binary ( 1 if the represented characteristic is present, 0 otherwise). All variables represent the characteristics of one of the road sides (near or off) in relation to the direction of movement under consideration.

\subsection{Usage of a 'Composite', 'Virtual' and 'Conservative' Expert}

Previous work (Correia, Bastos Silva 2011) has shown that one must expect a certain degree of disagreement between the speed limit selections assumed by different experts. In fact, in that work it was reported that in only $45 \%$ of the cases the selections were unanimous, although in $81 \%$ of them 3 out of 4 evaluations were consensual.

Although the MNL regression is naturally equipped to deal with these differences between different observers' evaluations, it tends to produce models representing 'average' assessments, in spite of the fact that the models will present probabilities for each alternative. Since in safety related problems it is recommended to use 'conservative', rather than 'average', options when traffic operational conditions are to be selected, it was decided to develop a new family of models based on the modelling of the options of a 'virtual conservative expert', selecting for each stretch of road the second most restrictive speed limit choice from the choices made by the 4 experts (554 cases). Methodologically, this new approach has also the advantage of making it simpler to assess the adherence between the results proposed by the models and the reference experts' options.

\subsection{Modelling Technique Formulation}

Because the current problem is a discrete choice one, the development of the new models was made based on MNL regression techniques. Discrete choice models are based in the theory of stochastic utility, whereby a choice is made by a decision maker in order to maximize his utility function. This utility function is constructed as a combination of known explanatory variables, the systematic part of utility, and a random part which is unknown (Ben-Akiva, Lerman 1985):

$$
U_{i n}=V_{i n}+\varepsilon_{i n}
$$

where: $V_{\text {in }}$ represents the systematic part of the utility given by decision maker $n$ to alternative $i$ (is generally considered as a linear-in-parameters of the form: $V_{i n}=\beta_{0 i}+\beta x_{i n}$, where: $x_{i n}$ is a vector of attribute values for alternative $i$ as viewed by decision maker $n$ and $\beta_{0 i}$ is a constant that is specific to alternative $i$ ); $\varepsilon_{\text {in }}$ represents the error between the systematic part of utility and the true utility given by user $n$ to alternative $i$.

Making assumptions on the error term of the utility expression conduces to different discrete choice models. As seen elsewhere (Ben-Akiva, Lerman 1985) the MNL model arises from the assumption that $\varepsilon_{n}=\varepsilon_{j n}+\varepsilon_{i n}$ is logistically distributed. Under this assumption, one can use a model expanded for multiple choices producing a MNL model expressed in the following way:

$$
P_{n}(i)=\text { Probability }\left(U_{i n} \geq U_{j n}\right)=\frac{e^{V_{i n}}}{\sum_{j \in C_{n}} e^{V_{j n}}},
$$

where: $C_{n}$ is the choice set that the decision maker faces.

The estimation of such model is best done by maximum likelihood, using a likelihood function, which can be presented in a linear form:

$$
\sum_{n=1}^{N} \sum_{i \in C_{n}} y_{i n}\left(\beta x_{i n}-\ln \sum_{j \in C_{n}} e^{\beta x_{j n}}\right),
$$

where: $y_{\text {in }}$ denotes the binary variable which is equal to 1 when respondent $n$ chooses alternative $i$, and 0 otherwise, and which should be maximized in order to produce the desired $\beta$ parameters.

\section{Factor Analysis}

In order to evaluate the underlying structure of the variables set, and the interrelations among them, a factorial analysis was carried out. This type of analysis enables the identification of common features amongst observed variables not directly observable. The observed variables are modelled as linear combinations of the potential factors. The information gained about the interdependencies between observed variables can be used to reduce the set of variables in a dataset.

Thus, factorial analysis is a method of data reduction that uses the correlations between variables to estimate common factors, also known as variates, allowing to condense the information contained in the wider set of variables into a smaller one of composite dimensions. 
Thus, these factors can be considered as unobservable latent variables.

The resulting factorial model can be represented as:

$$
Z=\Lambda f_{1}+\eta \text {, }
$$

where: $Z$ is the vector of standardized variables; $f$ is the vector of common factors; $\eta$ is the vector of the specific factors and $\Lambda$ is the matrix of factor loadings. On the other hand, the correlation matrix $\Pi$ can be modelled by:

$$
\Pi=\Lambda \Lambda^{\prime}+\psi,
$$

where: $\psi$ is the diagonal matrix and $\Lambda^{\prime}$ is the transpose of $\Lambda$.

Therefore, since factor analysis is based on the correlation matrix of the involved variables, it requires a large sample size. According to Hair et al. (2009), the sample shall contain at least five times as many observations as the number of variables to be analysed. Since 554 statistical cases were considered - representing each one of the 227 stretches of the 4 itineraries, in both directions - for 33 variables (32 independent variables and SSPEED, the dependent variable), this general rule is verified. Moreover, the correlation between the considered variables was evaluated before performing the factor analysis. The correlation matrix analysis has shown no significant correlations between the different explanatory variables - the usual cut-off value of 0.8 for absolute correlation (Hensher 1994) was used and, therefore, no variables were excluded. The SPSS software was also used in this analysis.

The analysis was carried out by using the principal components method, with the number of factors to be extracted determined having into account eigenvalues bigger than 1 and $65 \%$ or more of the variance explained. Two analyses were performed, with and without factor rotation. Since the results obtained by the former were not more satisfactory than those of the later, without a more simplified factor structure, only the un-rotated analysis was eventually considered. The rotation method used was varimax, an orthogonal method. Taking into account that only the first nine factors present eigenvalues bigger than 1 (from factor 1, with an eigenvalue of 8.708 , till factor 9 , with one of 1.046 - the biggest variation occurs between factor 1 and factor 2, with an eigenvalue of 2.361), the cumulative percentage of the total explained variance reaches $65 \%$ at the 10 th factor, and the eigenvalues stabilize between the 8th (explained variance of $3.290 \%$ ) and the 9 th factors (3.169\%), a number of 9 factors was chosen (the 1st factor corresponds to an explained variance of $26.388 \%$, which is far above all the other factors).

The results obtained for the final factor analysis are represented in Table 3 . This matrix includes the factor loadings, which are the correlation of each variable and the respective factor, expressing the correspondence between the variable and the factor (Hair et al. 2009). Therefore, a higher factor loading value indicates a stronger explanatory capacity of the variable variation by the factor. According to Hair et al. (2009), factor-loading values between 0.3 and 0.4 express a minimum acceptable level of significance of the variable in each factor.
A number of modelling results justify a special reference, the first being that Factor 1 is by far the one with more variables significantly related, with the majority of them being only associated to this factor. This group includes the dependent variable (SSPEED), whose factor loading is far higher than those of the remaining factors. Thus, Factor 1 can be regarded as a useful indicator of the variables with higher influence on SSPEED variation. It is also relevant to notice that the only variables with non-significant factor loading values were NAPARR, NAPARL, NGASR, NGASL, SIDEWR, SIDEWL and ISLAND, with the later presenting a particularly low value. As a result, it can be concluded that the presence of on-road parking spaces, filling stations and sidewalks on both sides of the road, as well as of a central island, is not significant to define the speed limit of a specific road stretch. On the other hand, the most relevant variables besides SSPEED (i.e., with higher factor loading values) are EDR, EDL, MDR, MDL, MEDR and MEDL. Nevertheless, the substantial number of variables associated with Factor 1 indicates that the variable selection was adequate. Finally, the other factors do not assume a structure coherent enough to reach any further conclusions.

In order to determine the appropriateness of the analysis, some tests were carried out. The Bartlett's sphericity test allows to evaluate the presence of correlations among variables. Thus, the statistical significance of this test $(\sigma<0.05)$ indicates that there are sufficient correlations among the variables (Hair et al. 2009). On the other hand, the Kaiser-Meyer-Olkin Measure of Sampling Adequacy (KMO MSA) evaluates the intercorrelations among the variables, and ranges from 0 to 1 . According to Hair et al. (2009), a value of 0.8 or over is considered to be suitable. In both tests, the obtained results are adequate $(\sigma=0.00$ in the Bartlett's sphericity test; 0.835 for the KMO MSA). Another measure of sampling adequacy, but specific for each variable, are the values of the diagonal of the anti-image correlation matrix, which can be interpreted in a similar way to the KMO MSA. All the obtained values are over 0.7 , which according to Hair et al. (2009) is considered to be adequate.

\section{Speed Limit Models' Development}

Taking advantage of the results obtained in the factor analysis, a number of MNL models, capable of evaluating the utility level corresponding to each of the speed limits alternatives, were developed. For the purpose of the present problem, for each road stretch, the alternative with the highest probability of occurrence was selected as the models' choice, representing the best option for the road speed limit at each location. The $90 \mathrm{~km} / \mathrm{h}$ $(56 \mathrm{mph})$ alternative was adopted as reference choice, because it is the standard design speed for a rural twolane highway in Portugal and many other countries, and because it facilitates the results interpretation, both in terms of values' and coefficients signs' coherence associated to each explanatory variable. This option also facilitates the identification of the variables which represent characteristics less compatible with significant traffic speeds, and which thus suggest the adoption of 70 or $50 \mathrm{~km} / \mathrm{h}$ (43 or $31 \mathrm{mph}$ ). 
Table 3. Component matrix for factor analysis

\begin{tabular}{|c|c|c|c|c|c|c|c|c|c|}
\hline Variable & 1 & 2 & 3 & 4 & 5 & 6 & 7 & 8 & 9 \\
\hline INTERR & 0.415 & 0.283 & 0.074 & -0.068 & 0.193 & -0.216 & 0.033 & -0.020 & -0.204 \\
\hline INTERL & 0.413 & 0.284 & -0.023 & -0.085 & 0.197 & -0.206 & -0.046 & -0.175 & -0.149 \\
\hline GARAGR & 0.462 & -0.002 & 0.000 & 0.465 & 0.305 & 0.225 & 0.251 & 0.151 & 0.145 \\
\hline GARAGL & 0.460 & 0.008 & -0.135 & 0.446 & 0.299 & 0.227 & -0.262 & -0.046 & 0.226 \\
\hline NATERR & 0.452 & 0.034 & -0.192 & -0.121 & -0.469 & -0.033 & 0.226 & 0.147 & 0.299 \\
\hline NATERL & 0.453 & 0.017 & 0.207 & -0.063 & -0.486 & -0.029 & -0.192 & 0.060 & 0.322 \\
\hline NAPARR & 0.270 & 0.175 & -0.305 & -0.204 & -0.199 & 0.345 & 0.225 & -0.113 & -0.182 \\
\hline NAPARL & 0.273 & 0.142 & 0.360 & -0.114 & -0.202 & 0.350 & -0.222 & -0.083 & -0.165 \\
\hline NAPEDR & 0.594 & 0.288 & -0.116 & 0.005 & -0.338 & 0.051 & 0.240 & 0.134 & 0.168 \\
\hline NAPEDL & 0.597 & 0.273 & 0.124 & 0.040 & -0.351 & 0.052 & -0.209 & -0.047 & 0.219 \\
\hline NAPEHR & 0.532 & 0.232 & -0.099 & 0.438 & 0.094 & 0.139 & 0.213 & 0.174 & 0.016 \\
\hline NAPEHL & 0.526 & 0.237 & -0.008 & 0.454 & 0.091 & 0.150 & -0.228 & -0.144 & 0.136 \\
\hline NBUSR & 0.305 & 0.429 & 0.006 & -0.349 & 0.219 & -0.355 & 0.001 & 0.010 & 0.271 \\
\hline NBUSL & 0.305 & 0.425 & 0.130 & -0.319 & 0.200 & -0.364 & 0.007 & 0.057 & 0.265 \\
\hline NCRO & 0.575 & 0.442 & 0.045 & -0.203 & 0.214 & 0.114 & -0.008 & 0.040 & -0.075 \\
\hline NGASR & 0.342 & 0.334 & -0.517 & -0.303 & 0.009 & 0.142 & -0.153 & 0.060 & -0.225 \\
\hline NGASL & 0.347 & 0.279 & 0.604 & -0.132 & 0.003 & 0.145 & 0.142 & -0.080 & -0.178 \\
\hline SIGNR & 0.415 & 0.121 & 0.466 & 0.087 & 0.313 & 0.098 & 0.161 & -0.021 & 0.050 \\
\hline SIGNL & 0.396 & 0.191 & -0.464 & -0.038 & 0.307 & 0.103 & -0.186 & 0.096 & 0.043 \\
\hline SIDEWR & 0.320 & 0.185 & 0.492 & 0.059 & -0.206 & 0.234 & 0.102 & 0.088 & -0.244 \\
\hline SIDEWL & 0.322 & 0.222 & -0.474 & -0.076 & -0.214 & 0.228 & -0.086 & -0.155 & -0.192 \\
\hline ISLAND & 0.066 & -0.035 & 0.069 & -0.313 & 0.319 & 0.063 & -0.020 & 0.028 & -0.092 \\
\hline AVCOR & 0.409 & -0.424 & 0.097 & -0.348 & 0.170 & 0.305 & -0.151 & -0.319 & 0.235 \\
\hline AVCOL & 0.438 & -0.388 & -0.035 & -0.338 & 0.185 & 0.236 & 0.157 & 0.428 & 0.057 \\
\hline HICOR & 0.580 & -0.047 & -0.132 & 0.259 & -0.133 & -0.373 & 0.345 & 0.035 & -0.244 \\
\hline HICOL & 0.573 & -0.047 & 0.045 & 0.277 & -0.190 & -0.367 & -0.344 & -0.176 & -0.191 \\
\hline EDR & 0.750 & -0.245 & -0.090 & 0.133 & 0.059 & -0.138 & 0.172 & -0.228 & -0.045 \\
\hline EDL & 0.751 & -0.245 & 0.027 & 0.146 & 0.029 & -0.163 & -0.173 & 0.176 & -0.157 \\
\hline MDR & -0.778 & 0.360 & 0.037 & 0.132 & -0.028 & 0.060 & -0.208 & 0.342 & -0.040 \\
\hline MDL & -0.776 & 0.361 & -0.033 & 0.118 & 0.004 & 0.104 & 0.218 & -0.311 & 0.131 \\
\hline MEDR & -0.689 & 0.364 & 0.087 & 0.147 & -0.017 & -0.010 & -0.196 & 0.355 & -0.083 \\
\hline MEDL & -0.688 & 0.366 & -0.081 & 0.113 & 0.025 & 0.033 & 0.215 & -0.340 & 0.101 \\
\hline SSPEED & -0.718 & 0.115 & -0.043 & 0.090 & 0.031 & 0.028 & -0.006 & 0.036 & 0.045 \\
\hline
\end{tabular}

Note: The names of the variables in the model use the $\mathrm{R}$ and $\mathrm{L}$ letters to differentiate nearside (Right) and offside of the road (Left). Portugal is a country with right-hand traffic.

The first part of the work dealt with the development of two MNL models where the reference speed limits, which were to be explained by the models corresponded to the independent assessments made by 4 experts for each of the stretches of the different modelling itineraries. The number of statistical cases correspond to 2216 cases ( 277 stretches $\times 2$ ways $\times 4$ experts). The two models were: Model I, in which the surrounding environmental characteristics were represented by subjective variables (AVCOR (L), HICOR (L) presented on Table 1); Model II, in which the surrounding environmental characteristics were represented by the set of objective variables (EDR (L), MDR (L) and MEDR (L)). The MNL modelling technique was applied in the way described above using the SPSS application.

The correlation matrix analysis has shown no significant correlations between the different explanatory variables (as previously referred, a cut-off of 0.8 was adopted), which led to maintaining all variables in the modelling process. Models I and II corresponding McFadden pseudo- $R^{2}$ were respectively 0.274 and 0.344 , which represent quite reasonable results (see Tables 4 and 5). According to the mapping of the pseudo- $R^{2}$ to the linear $R^{2}$ derived by Domencich and McFadden (1975), $0.35 / 0.45$ pseudo- $R^{2}$ would correspond to linear model $R^{2}$ of about $0.7 / 0.85$, respectively. Further, a McFadden pseudo- $R^{2}$ of 0.35 corresponds to a Nagelkerke pseudo- $R^{2}$ of approximately 0.5 .

The results also proved to be extremely consistent, with all the signs associated to the coefficients of the explanatory variables being positive (exception for $M D$ variables), reflecting an increase in the utility of the more restrictive speed limits' alternatives when the value of the explanatory variables increase. It is also evident the generic increase of the magnitude of the coefficients associated with the $50 \mathrm{~km} / \mathrm{h}$ alternative utility in relation to those associated with the $70 \mathrm{~km} / \mathrm{h}$ one. Also, as expected, a tendency for a stronger and more frequent integration of the variables representing the nearside of the road traffic flow was observed, indicating that the experts, despite taking into consideration the characteristics of both sides of the surrounding environment, 
Table 4. Calibrated coefficients for the MNL Model I - 'Average Expert'

\begin{tabular}{|c|c|c|c|c|c|c|c|c|c|c|c|}
\hline \multicolumn{7}{|c|}{$50 \mathrm{~km} / \mathrm{h}(31 \mathrm{mph})$ utility coefficients } & \multicolumn{5}{c|}{$70 \mathrm{~km} / \mathrm{h}(43 \mathrm{mph})$ utility coefficients } \\
\hline \multicolumn{7}{|c|}{ Model I - subjective explanatory variables (McFadden pseudo- $\left.R^{2}=0.274\right)$} \\
\hline Variable & $\beta$ & Std. error & $\exp (\beta)$ & $\sigma$ & Variable & $\beta$ & Std. error & $\exp (\beta)$ & $\sigma$ \\
\hline 50 Intercept & -4.199 & 0.193 & - & 0 & 70 Intercept & -1.206 & 0.077 & - & 0 \\
\hline INTERR & 0.855 & 0.161 & 2.352 & 0 & INTERR & 0.505 & 0.116 & 1.658 & 0 \\
\hline INTERL & 0.513 & 0.162 & 1.671 & 0.001 & INTERL & 0.349 & 0.114 & 1.417 & 0.002 \\
\hline GARAGR & 0.227 & 0.063 & 1.255 & 0 & GARAGR & \multicolumn{2}{|c|}{ not significant thus not included } \\
\hline NATERL & 0.390 & 0.073 & 1.477 & 0 & NATERL & 0.259 & 0.058 & 1.296 & 0 \\
\hline SIDEWR & 1.711 & 0.332 & 5.535 & 0 & SIDEWR & 0.708 & 0.263 & 2.030 & 0.007 \\
\hline SIDEWL & 1.600 & 0.302 & 4.951 & 0 & SIDEWL & \multicolumn{1}{|c|}{ not significant thus not included } \\
\hline NBUSR & 0.858 & 0.298 & 2.358 & 0.004 & NBUSR & 0.947 & 0.217 & 2.579 & 0 \\
\hline TLIGHR & 1.192 & 0.365 & 3.294 & 0.001 & TLIGHR & 0.862 & 0.329 & 2.369 & 0.009 \\
\hline AVCOR & 2.026 & 0.218 & 7.582 & 0 & AVCOR & 1.193 & 0.150 & 3.298 & 0 \\
\hline AVCOL & 1.335 & 0.219 & 3.800 & 0 & AVCOL & 0.927 & 0.158 & 2.527 & 0 \\
\hline HICOR & 3.032 & 0.406 & 20.733 & 0 & HICOR & 2.008 & 0.372 & 7.447 & 0 \\
\hline HICOL & 2.671 & 0.406 & 14.450 & 0 & HICOL & 1.450 & 0.379 & 4.261 & 0 \\
\hline
\end{tabular}

Note: The names of the variables in the model use the $\mathrm{R}$ and $\mathrm{L}$ letters to differentiate nearside (Right) and offside of the road (Left). Portugal is a country with right-hand traffic.

Table 5. Calibrated coefficients for the MNL Model II - 'Average Expert'

\begin{tabular}{|c|c|c|c|c|c|c|c|c|c|c|}
\hline \multicolumn{7}{|c|}{$50 \mathrm{~km} / \mathrm{h}(31 \mathrm{mph})$ utility coefficients } & \multicolumn{5}{c|}{$70 \mathrm{~km} / \mathrm{h}(43 \mathrm{mph})$ utility coefficients } \\
\hline \multicolumn{9}{|c|}{ Model II - objective explanatory variables (McFadden pseudo- $\left.R^{2}=0.344\right)$} \\
\hline Variable & $\beta$ & Std. error & $\exp (\beta)$ & $\sigma$ & Variable & $\beta$ & \multicolumn{2}{|c|}{ Std. error } & $\exp (\beta)$ & $\sigma$ \\
\hline 50 Intercept & - & - & - & 0 & 70 Intercept & - & - & - & 0 \\
\hline INTERR & 0.794 & 0.161 & 2.213 & 0 & INTERR & 0.497 & 0.118 & 1.644 & 0 \\
\hline INTERL & 0.504 & 0.161 & 1.655 & 0.002 & INTERL & 0.338 & 0.115 & 1.402 & 0.003 \\
\hline GARAGR & 0.249 & 0.064 & 1.282 & 0 & GARAGR & 0.127 & 0.056 & 1.135 & 0.02 \\
\hline NATERL & 0.427 & 0.071 & 1.533 & 0 & NATERL & 0.323 & 0.059 & 1.382 & 0 \\
\hline SIDEWR & 1.557 & 0.332 & 4.745 & 0 & SIDEWR & 0.659 & 0.269 & 1.932 & 0.01 \\
\hline SIDEWL & 1.443 & 0.300 & 4.233 & 0 & SIDEWL & not significant thus not included \\
\hline NBUSL & 0.561 & 0.290 & 1.752 & 0.05 & NBUSL & 0.696 & 0.221 & 2.006 & 0.002 \\
\hline TLIGHR & 1.022 & 0.367 & 2.778 & 0.005 & TLIGHR & 0.734 & 0.331 & 2.083 & 0.03 \\
\hline ISLAND & \multicolumn{3}{|c|}{ not significant thus not included } & ISLAND & 0.862 & 0.154 & 2.367 & 0 \\
\hline MDR & -0.086 & 0.009 & 0.917 & 0 & MDR & -0.030 & 0.006 & 0.970 & 0 \\
\hline MDL & -0.069 & 0.009 & 0.934 & 0 & MDL & -0.020 & 0.006 & 0.980 & 0.001 \\
\hline EDR & 0.149 & 0.070 & 1.161 & 0.03 & EDR & 0.209 & 0.056 & 1.232 & 0 \\
\hline EDL & 0.188 & 0.074 & 1.207 & 0.01 & EDL & 0.228 & 0.059 & 1.256 & 0 \\
\hline
\end{tabular}

Note: The names of the variables in the model use the $\mathrm{R}$ and $\mathrm{L}$ letters to differentiate nearside (Right) and offside of the road (Left). Portugal is a country with right-hand traffic.

tend to valuate more the nearside over the offside of the traffic flow (which is in accordance with the factor analysis results). Exceptions to this general tendency appear on a limited number of variables (ED in Model II), which is thought to be due to collinearity phenomena.

The substitution of the subjective variables representing the surrounding environment has enabled a moderate increase in the pseudo- $R^{2}$ McFadden of Model II in relation to the one corresponding to Model I (0.274 and 0.344 , respectively). However, more importantly, Model II presents itself as very consistent and robust. The signs of the coefficients associated with the minimum distance between buildings and the carriageway (MDR and MDL) and those of the coefficients associated with the surrounding Edification density (EDR and EDL) have proved to be negative and positive, as expected. The variables MED were removed from the model due to their significant correlation (around 0.88) in relation with the corresponding MD ones. It should be noticed that the models totally based on objective explanatory variables represents a significant improvement of the quality and robustness of the final model 
since it improves the good fitness (higher pseudo- $R^{2}$ ), and represents a significant edge in terms of practical applicability and transferability between different locations and countries.

The second part of this MNL modelling process focused on the development of models where the reference speed limits, which were to be explained by the models, corresponded to the second most conservative proposal from the assessments made by 4 experts for each one of the 554 stretches of road.

From this analysis, two more MNL models were developed: Model III corresponding to the use of the subjective variables, which represent the surrounding environment characteristics; Model IV corresponding to the use of the objective variables representing the surrounding environment characteristics (see Tables 6 and 7). This new modelling strategy has, as expected, resulted in a significant increase in the pseudo- $R^{2}$ of McFadden (respectively 0.413 and 0.447 for Models III and IV) in relation to the values obtained for Models I and II while maintaining their consistency levels. This is explained because Models III and IV do not have to incorporate the experts' existing, although not significant, differences of opinion. However, the most interest-

Table 6. Calibrated coefficients for the MNL Model III - 'Virtual Conservative Expert'

\begin{tabular}{|c|c|c|c|c|c|c|c|c|c|c|}
\hline \multicolumn{7}{|c|}{$50 \mathrm{~km} / \mathrm{h}(31 \mathrm{mph})$ utility coefficients } & \multicolumn{5}{c|}{$70 \mathrm{~km} / \mathrm{h}(43.5 \mathrm{mph})$ utility coefficients } \\
\hline \multicolumn{4}{|c|}{ Model III - subjective explanatory variables (McFadden pseudo- $\left.R^{2}=0.413\right)$} \\
\hline Variable & $\beta$ & Std. error & $\exp (\beta)$ & $\sigma$ & Variable & $\beta$ & Std. error & $\exp (\beta)$ & $\sigma$ \\
\hline 50 Intercept & -5.127 & 0.416 & - & 0 & 70 Intercept & -1.542 & 0.163 & - & 0 \\
\hline INTERR & 1.500 & 0.347 & 4.483 & 0 & INTERR & 1.216 & 0.263 & 3.374 & 0 \\
\hline INTERL & 1.016 & 0.350 & 2.763 & 0.004 & INTERL & 0.907 & 0.262 & 2.477 & 0.001 \\
\hline GARAGR & 0.875 & 0.221 & 2.399 & 0 & GARAGR & 0.754 & 0.210 & 2.126 & 0 \\
\hline NATERL & 0.836 & 0.193 & 2.307 & 0 & NATERL & 0.550 & 0.163 & 1.733 & 0.001 \\
\hline SIDEWR & 3.547 & 0.780 & 34.718 & 0 & SIDEWR & & not significant thus not included \\
\hline SIDEWL & 3.463 & 0.757 & 31.927 & 0 & SIDEWL & 1.330 & 0.654 & 3.782 & 0.042 \\
\hline NBUSL & 1.738 & 0.727 & 5.683 & 0.017 & NCRO & 2.077 & 0.577 & 7.978 & 0 \\
\hline AVCOR & 2.287 & 0.479 & 9.840 & 0 & NBUSR & 1.016 & 0.354 & 2.761 & 0.004 \\
\hline AVCOL & 1.637 & 0.478 & 5.140 & 0.001 & TLIGHR & 1.076 & 0.369 & 2.932 & 0.004 \\
\hline HICOR & 2.072 & 0.428 & 7.941 & 0 & AVCOR & 1.748 & 0 & 5.743 & 0 \\
\hline HICOL & 2.883 & 0.424 & 17.868 & 0 & AVCOL & 2.012 & 0 & 7.481 & 0 \\
\hline
\end{tabular}

Note: The names of the variables in the model use the $\mathrm{R}$ and $\mathrm{L}$ letters to differentiate nearside (Right) and offside of the road (Left). Portugal is a country with right-hand traffic.

Table 7. Calibrated coefficients for the MNL Model IV - 'Virtual Conservative Expert'

\begin{tabular}{|c|c|c|c|c|c|c|c|c|c|c|}
\hline \multicolumn{7}{|c|}{$50 \mathrm{~km} / \mathrm{h}(31 \mathrm{mph})$ utility coefficients } & \multicolumn{7}{c|}{$70 \mathrm{~km} / \mathrm{h}(43.5 \mathrm{mph})$ utility coefficients } \\
\hline \multicolumn{7}{|c|}{ Model IV - objective explanatory variables (McFadden pseudo- $\left.R^{2}=0.447\right)$} \\
\hline Variable & $\beta$ & Std. error & $\exp (\beta)$ & $\sigma$ & Variable & $\beta$ & Std. error & $\exp (\beta)$ & $\sigma$ \\
\hline 50 Intercept & - & - & - & - & 70 Intercept & - & - & - & - \\
\hline INTERR & 1.480 & 0.350 & 4.395 & 0 & INTERR & 1.265 & 0.270 & 3.542 & 0 \\
\hline INTERL & 1.093 & 0.346 & 2.982 & 0.002 & INTERL & 1.012 & 0.263 & 2.751 & 0 \\
\hline GARAGR & 0.857 & 0.209 & 2.357 & 0 & GARAGR & 0.805 & 0.196 & 2.237 & 0 \\
\hline NATERL & 0.908 & 0.187 & 2.480 & 0 & NATERL & 0.655 & 0.163 & 1.924 & 0 \\
\hline SIDEWR & 3.597 & 0.821 & 36.481 & 0 & SIDEWR & 1.415 & 0.696 & 4.116 & 0.04 \\
\hline SIDEWL & 3.245 & 0.810 & 25.653 & 0 & SIDEWL & 1.399 & 0.677 & 4.049 & 0.04 \\
\hline NBUSL & \multicolumn{2}{|c|}{ not significant thus not included } & NBUSL & 1.781 & 0.591 & 5.935 & 0.003 \\
\hline MDR & -0.115 & 0.020 & 0.892 & 0 & MDR & -0.042 & 0.013 & 0.959 & 0.001 \\
\hline MDL & -0.091 & 0.020 & 0.913 & 0 & MDL & not significant thus not included \\
\hline EDR & 0.267 & 0.155 & 1.306 & 0.05 & EDR & not significant thus not included \\
\hline EDL & 3.216 & 0.566 & 24.938 & 0.05 & EDL & 2.496 & 0.385 & 12.140 & 0.05 \\
\hline
\end{tabular}

Note: The names of the variables in the model use the $\mathrm{R}$ and $\mathrm{L}$ letters to differentiate nearside (Right) and offside of the road (Left). Portugal is a country with right-hand traffic. 
ing characteristic associated to this new type of model is that, as it was explained before, it facilitates the interpretation of validation results, and particularly because it can be developed to represent different levels of safety related sensitivity existent on the expert communities.

In order to evaluate the robustness of the model (only Model IV was analysed), a residual analysis was carried out. According to Hauer and Bamfo (1997), if the model function presents a random walk around 0 , with a final value equal or close to 0 , and if its values are contained within a band representing the double of the standard deviation value $\sigma$, the model adequately fits the data. This analysis was carried out for both non-reference alternatives and to all of the continuous independent variables, namely for MDR, MDL, MEDR, MEDL, EDR and EDL. The obtained results are presented in Figs 1 and 2, for two application examples for each one of the alternatives.

These results show a better data fit in the $50 \mathrm{~km} / \mathrm{h}$ alternative. However, the cumulative residuals function for each one of the explanatory variables under analysis tends to 0 , and remains within the admissible range of values, established by $2 \sigma$. The only exception was obtained for EDL in the $70 \mathrm{~km} / \mathrm{h}$ alternative, where the function intersects the $2 \sigma$ band, but only in some isolated points. Therefore, it is possible to conclude that the developed models have a high degree of robustness and appropriately represent the observed variability.

\section{Model Validation}

The models' real capability to predict and explain the selected speed limit in each stretch was validated using an independent data set, totalling 110 stretches of 200 $\mathrm{m}$ collected in a different $11 \mathrm{~km}$ itinerary, and comparing the results with those obtained by the models using the modelling data set obtained from the initial 4 itineraries. As referred before, both the modelling and

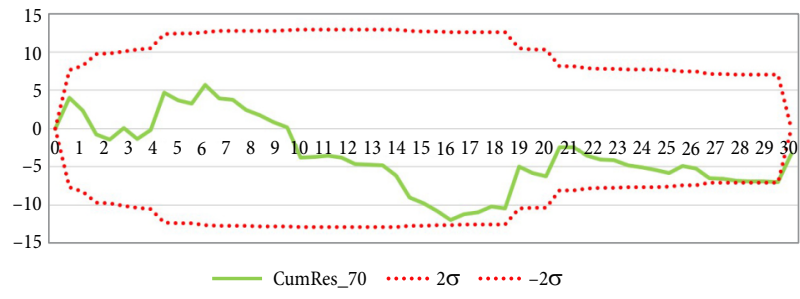

Fig. 1. Cumulative residuals for MDR, $70 \mathrm{~km} / \mathrm{h}$ alternative

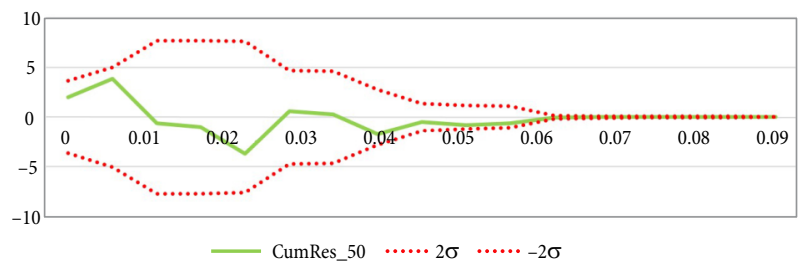

Fig. 2. Cumulative residuals for EDL, $50 \mathrm{~km} / \mathrm{h}$ alternative

validation itineraries presented an adequate mix of geometrical, operational and surrounding environmental characteristics, typical of single carriageway, two-lane rural highways.

The methodology adopted for the validation process consisted on a separate comparison of Models III and IV predictions for each one of the 110 validation stretches and each one of the 554 modelling stretches, against the corresponding speed limits selected by the 'virtual conservative expert' approach. The obtained results are presented on Table 8 .

The results show a high level of correlation between model results and 'virtual conservative expert' assessments. However, surprisingly, the results proved to be even better with the validation data set than with the initial modelling data set. It is hypothesized that this is due to the fact that the validation itinerary presents slightly easier to identify boundaries between the different types of road's surrounding environments.

Table 8. MNL validation model - 'Virtual Conservative Expert' vs 'Conservative expert Models' III and IV

\begin{tabular}{|c|c|c|c|c|c|c|c|c|c|}
\hline \multirow{4}{*}{$\begin{array}{c}\text { Virtual conservative } \\
\text { expert choices } \\
{[\mathrm{km} / \mathrm{h}]}\end{array}$} & \multirow{4}{*}{$\begin{array}{l}\text { Models' } \\
\text { choices } \\
{[\mathrm{km} / \mathrm{h}]}\end{array}$} & \multicolumn{4}{|c|}{ Modelling set } & \multicolumn{4}{|c|}{ Validation set } \\
\hline & & \multicolumn{2}{|c|}{ Model III } & \multicolumn{2}{|c|}{ Model IV } & \multicolumn{2}{|c|}{ Model III } & \multicolumn{2}{|c|}{ Model IV } \\
\hline & & No & $\%$ & No & $\%$ & No & $\%$ & No & $\%$ \\
\hline & & 554 & - & 554 & - & 110 & - & 110 & - \\
\hline \multirow{4}{*}{50} & - & 95 & 100 & 95 & 100 & 24 & 100 & 24 & 100 \\
\hline & 50 & 59 & 62.1 & 67 & 71.0 & 18 & 75.0 & 18 & 75.0 \\
\hline & 70 & 34 & 35.8 & 26 & 27.0 & 4 & 16.7 & 4 & 16.7 \\
\hline & 90 & 2 & 2.11 & 2 & 2.0 & 2 & 8.3 & 2 & 8.3 \\
\hline \multirow{4}{*}{70} & - & 240 & 100 & 240 & 100 & 32 & 100 & 32 & 100 \\
\hline & 50 & 22 & 9.2 & 23 & 9.58 & 4 & 12.5 & 4 & 12.5 \\
\hline & 70 & 140 & 58.3 & 142 & 59.2 & 22 & 68.8 & 22 & 68.8 \\
\hline & 90 & 78 & 32.5 & 75 & 31.3 & 6 & 18.8 & 6 & 18.8 \\
\hline \multirow{4}{*}{90} & & 219 & 100 & 219 & 100 & 54 & 100 & 54 & 100 \\
\hline & 50 & 0 & 0 & 1 & 0.4 & 0 & 0 & 0 & 0 \\
\hline & 70 & 35 & 16.0 & 33 & 15.1 & 5 & 9,3 & 5 & 9.3 \\
\hline & 90 & 184 & 84.0 & 185 & 84.5 & 49 & 90.7 & 49 & 90.7 \\
\hline \multicolumn{2}{|c|}{ Average $\%$ of concurrent choices } & \multicolumn{2}{|c|}{$69.13 \%$} & \multicolumn{2}{|c|}{$71.12 \%$} & \multicolumn{2}{|c|}{$80.91 \%$} & \multicolumn{2}{|c|}{$80.91 \%$} \\
\hline
\end{tabular}


Generally, both Models III and IV seem capable of adequately represent the assessments of the 'virtual conservative expert' in approximately $70 \%$ of the situations. Furthermore, the number of cases in which the difference between the expert assessment and the model prediction is of more than one level $(50 \mathrm{~km} / \mathrm{h}$ vs $90 \mathrm{~km} / \mathrm{h})$ is extremely low. This leads to the conclusion that there is a fairly good consistency and accuracy of Models III and IV in predicting the 'virtual conservative expert' judgment, proving them capable of supporting a decision supporting system to select speed limits.

However, in spite of the adherence of the results provided by Model IV being only moderately higher than the one provided by Model III, it is considered that Model IV results are significantly more robust because it uses only objective data to quantify all explanatory variables, giving it a much higher degree of transferability and practical applicability in different locations and countries, justifying a modest increase in the effort needed to collect the input data.

\section{Conclusions and Future Work}

Previous work has shown that MNL discrete choice models are adequate to apply to the problem of identifying adequate speed limits, selected from a limited number of alternative options. The present work represents a significant contribution for the development of robust models capable of giving objective support for selecting realistic speed limits alongside different stretches of two lane rural highways, crossing different (urban, rural, mixed) surrounding environments in different countries.

The developed work has centered on:

- selecting a complete set of objective and easily measurable explanatory variables to be used in the models, without losing their explanatory capabilities;

- performing a factor analysis in an preliminary modelling stage, to evaluate the underlying structure of the variables set;

- developing models based on reproducing consensual 'conservative' assessments based on highway and safety experts' evaluations, instead of an approach based on 'average' experts' evaluations; specific attention was given to the identification of objective variables capable of representing the level of roads' lateral restrictions, which have previously proved to be of significant importance, but which have up to now been represented by subjective variables that are difficult to specify in the same way in different locations and by different observers.

The factor analysis, carried out with the whole set of variables, allowed to conclude that the majority of the selected variables have a significant influence over the independent variable (speed limit, in this case) variation, with those related with lateral restrictions and edification density in the surrounding areas as the most relevant. Since these are the objective explanatory variables previously defined to improve the model, it can be concluded that the variable selection and definition process was adequate.

The subsequent MNL modelling process led to the development of models, which represent the assessments of a 'virtual conservative expert', which is defined through the selection of the second most conservative evaluation made by 4 different experts, for each stretch of road. This modelling approach has proved capable of producing consistent results, which compare very well with previous modelling approaches based on the representation of 'an average group of experts', and even increasing their explanatory capabilities. Furthermore, this approach enables the models to be developed to represent different levels of safety related sensitivity existent on the expert communities. The two models based on the judgment of a 'virtual, conservative expert', have proved capable of incorporating a decision supporting system to select roads' speed limits, balancing safety and people's expectations and, in this perspective, improving the driving task and the risk perception associated with different road environments, contributing for the credibility of traffic signalling and its compliance levels.

Model IV is considered to be specially promising because, not only its $R^{2}$ results being only moderately higher than those provided by Model III, it is considered that Model IV is more robust, because it only uses objective data to quantify all explanatory variables, giving it a much higher degree of transferability and practical applicability in different locations and countries. Furthermore, its use reveals itself to be extremely simple, with the new objective explanatory variables being easily measurable, although through some effort, and mostly obtainable using Google Maps type of images.

Nonetheless, it is apparent that there is still room for further development and validation of these models. More specifically, one should aim to identify other variables that might have the potential to help in the determination of these adequate speed limits. This selection ought to be supported by a careful evaluation of the points where the expert assessment is less well matched by the models results. Especially relevant most likely will be to perform a thorough residual analysis to check if there exist aspects of the experts' evaluation criteria not being adequately explained, if at all, by any of the included explanatory variables, which might lead to the inclusion of new variables in the models. Adequate residual analysis processes will also enable a more detailed evaluation of the intra and inter experts' assessments (in)consistency. Another line of research should be the development of speed limits' setting methodologies that, besides the safety and users' natural expectancy aspects, also incorporate a cost-benefit perspective, by including aspects linked to the expected accidents, pollution, energy consumption or travel time costs. Some work should also be carried out in defining a methodology capable of supporting the definition of speed management strategies throughout extended lengths of routes, along which it is essential to guaranty consistent and smooth speed limits' profiles in accordance with drivers' expectancies and comfortable braking conditions in transition areas. 


\section{Acknowledgements}

The team thanks to Mais Centro/QREN/EU for funding the Project EMSURE - 'Energy and Mobility for Sustainable Regions' (CENTRO-07-0224-FEDER-002004).

\section{References}

Aarts, L.; Van Schagen, I. V. 2006. Driving speed and the risk of road crashes: a review, Accident Analysis \& Prevention 38(2): 215-224. http://doi.org/10.1016/j.aap.2005.07.004

Agent, K.; Pigman, J.; Weber, J. 1998. Evaluation of speed limits in Kentucky, Transportation Research Record: Journal of the Transportation Research Board 1640: 57-64. http://doi.org/10.3141/1640-08

Austroads. 2009. Best Practice for Variable Speed Limits: Literature Review. Publication No AP-R342-09. Austroads, Sydney, Australia. 112 p. Available from Internet: https://www. onlinepublications.austroads.com.au/items/AP-R342-09

Austroads. 2005. Balance between Harm Reduction and Mobility in Setting Speed Limits: a Feasibility Study. Publication No AP-R272-05. Austroads, Sydney, Australia. 83 p. Available from Internet: https://www.onlinepublications. austroads.com.au/items/AP-R272-05

Ben-Akiva, M.; Lerman, S. R. 1985. Discrete Choice Analysis: Theory and Application to Travel Demand. The MIT Press. $384 \mathrm{p}$.

Correia, G. H. A.; Bastos Silva, A. 2011. Setting speed limits on rural two-lane highways by modeling the relationship between expert judgment and measurable roadside characteristics, Journal of Transportation Engineering 137(3): 184192. http://doi.org/10.1061/(ASCE)TE.1943-5436.0000210

Correia, G. H. A.; Bastos Silva, A. M. C. 2010. Setting speed limits in rural and interurban two-lane highways using expert opinion crossed with measurable roadside characteristics, in TRB 89th Annual Meeting Compendium of Papers DVD, 10-14 January 2010, Washington, DC, 1-16.

Cruzado, I.; Donnell, E. T. 2010. Factors affecting driver speed choice along two-lane rural highway transition zones, Journal of Transportation Engineering 136(8): 755-764. http://doi.org/10.1061/(ASCE)TE.1943-5436.0000137

Dell'Acqua, G. 2015. Modeling driver behavior by using the speed environment for two-lane rural roads, Transportation Research Record: Journal of the Transportation Research Board 2472: 83-90. http://doi.org/10.3141/2472-10

Dell'Acqua, G.; Mauro, R.; Russo, F. 2011. Descriptors in scenic highway analysis: a test study along Italian road corridors, International Journal for Traffic and Transport Engineering 1(2): 73-88.

Dell'Acqua, G.; Russo, F. 2011. Road performance evaluation using geometric consistency and pavement distress data, Transportation Research Record: Journal of the Transportation Research Board 2203: 194-202.

DfT. 2013. Setting Local Speed Limits. Department for Transport Circular 01/2013. London, UK. 42 p. Available from Internet: https:/www.gov.uk/government/uploads/system/ uploads/attachment_data/file/63975/circular-01-2013.pdf

Domencich, T.; McFadden, D. L. 1975. Urban Travel Demand: a Behavioral Analysis. North-Holland Publishing. 215 p.

Donnell, E.; Himes, S.; Mahoney, K.; Porter, R. 2009. Understanding speed concepts: key definitions and case study examples, Transportation Research Record: Journal of the Transportation Research Board 2120: 3-11. http://doi.org/10.3141/2120-01
Elvik, R. 2010. A restatement of the case for speed limits, Transport Policy 17(3): 196-204.

http://doi.org/10.1016/j.tranpol.2009.12.006

Elvik, R. 2002. Optimal speed limits: limits of optimality models, Transportation Research Record: Journal of the Transportation Research Board 1818: 32-38. http://doi.org/10.3141/1818-05

Farmer, C. M.; Retting, R. A.; Lund, A. K. 1999. Changes in motor vehicle occupant fatalities after repeal of the national maximum speed limit, Accident Analysis \& Prevention 31(5): 537-543. http://doi.org/10.1016/S0001-4575(99)00010-X

Fitzpatrick, K.; Carlson, P.; Brewer, M.; Wooldridge, M. 2001. Design factors that affect driver speed on suburban streets, Transportation Research Record: Journal of the Transportation Research Board 1751: 18-25. http://doi.org/10.3141/1751-03

Greibe, P.; Nilsson, P. K.; Herrstedt, L. 1999. Speed Management in Urban Areas: a Framework for the Planning and Evaluation Process. Report No 168. The Danish Road Directorate, Traffic Safety and Environment Division, Copenhagen, Denmark. 41 p.

Hair, J. F.; Black, W. C.; Babin, B. J.; Anderson, R. E. 2009. Multivariate Data Analysis. 7th edition. Pearson. 816 p.

Hallmark, S.; Hawkins, N.; Fitzsimmons, E.; Resler, J.; Plazak, D.; Welch, T.; Petersen, E. 2008. Use of physical devices for calming traffic along major roads through small rural communities in Iowa, Transportation Research Record: Journal of the Transportation Research Board 2078: 100-107. http://doi.org/10.3141/2078-14

Hauer, E. 2009. Speed and safety, Transportation Research Record: Journal of the Transportation Research Board 2103: 10-17. http://doi.org/10.3141/2103-02

Hauer, E.; Bamfo, J. 1997. Two tools for finding what function links the dependent variable to the explanatory variables, in Proceedings: ICTCT 97 Conference: International Cooperation on Theories and Concepts in Traffic Safety, 5-7 November 1997, Lund, Sweden, 1-18.

Hensher, D. A. 1994. Stated preference analysis of travel choices: the state of practice, Transportation 21(2): 107-133. http://doi.org/10.1007/BF01098788

Kockelman, K. 2006. Safety Impacts and Other Implications of Raised Speed Limits on High-Speed Roads. Final Report. Project Number: 17-23. National Cooperative Highway Research Program, Transportation Research Board, Washington, DC. 197 p. Available from Internet: http://onlinepubs. trb.org/onlinepubs/nchrp/nchrp_w90.pdf

Lave, C.; Elias, P. 1994. Did the 65 mph speed limit save lives?, Accident Analysis \& Prevention 26(1): 49-62. http://doi.org/10.1016/0001-4575(94)90068-X

Mackey, P. 2004. Context-sensitive design for rural speed management, in 2004 Annual Conference and Exhibition of the Transportation Association of Canada - Transportation Innovation - Accelerating the Pace, 19-22 September 2004, Quebec, Canada, 1-8.

Malyshkina, N.; Mannering, F. 2008. Effect of increases in speed limits on severities of injuries in accidents, Transportation Research Record: Journal of the Transportation Research Board 2083: 122-127. http://doi.org/10.3141/2083-14

Neuman, T. R.; Schwartz, M.; Clark, L.; Bednar, J. 2002. A Guide to Best Practices for Achieving Context Sensitive Solutions. NCHRP Report 480. National Cooperative Highway Research Program, Transportation Research Board, 
Washington, DC. 151 p. Available from Internet: http:// onlinepubs.trb.org/onlinepubs/nchrp/nchrp_rpt_480.pdf

Park, Y.-J.; Saccomanno, F. F. 2006. Evaluating speed consistency between successive elements of a two-lane rural highway, Transportation Research Part A: Policy and Practice 40(5): 375-385. http://doi.org/10.1016/j.tra.2005.08.003

Russo, F.; Fric, S.; Biancardo, S. A.; Gavran, D. 2015. Driver speed behavior on circular curves of undivided two-lane rural roads: Serbian and Italian case studies, Transportation Research Record: Journal of the Transportation Research Board 2472: 117-128. http://doi.org/10.3141/2472-14

Seco, A. J. M.; Bastos Silva, A. M. C; Galvão, C. S. A. 2008. Speed management in regional and national single carriageway through roads, in 2nd European Road Transport Research Arena TRA 2008, 21-24 April 2008, Ljubljana, Slovenia.

Srinivasan, R.; Parker, M.; Harkey, D.; Tharpe, D.; Sumner, R. 2006. An Expert System for Recommending Speed Limits in Speed Zones. Final Report. National Cooperative Highway Research Program. Transportation Research Board, Washington, DC. 71 p.

Stamatiadis, N. 2001. A European approach to context sensitive design, Transportation Quarterly 55(4): 41-48.

Stuster, J.; Coffman, Z.; Warren, D. 1998. Synthesis of Safety Research Related to Speed and Speed Management. Publication No FHWA-RD-98-154. Federal Highway Administration, McLean, VA. National Highway Traffic Safety Administration, Washington, DC. Available from Internet: http:// www.fhwa.dot.gov/publications/research/safety/98154

TRB. 2011. Speed Reduction Techniques for Rural High-to-Low Speed Transitions: a Synthesis of Highway Practice. NCHRP Synthesis 412. National Cooperative Highway Research Program, Transportation Research Board, Washington, DC. 114 p. Available from Internet: http://onlinepubs.trb. org/onlinepubs/nchrp/nchrp_syn_412.pdf

TRB. 1998. Management Speed: Review of Current Practice for Setting and Enforcing Speed Limits. Special Report 254. Transportation Research Board, Washington, DC. 441 p. Available from Internet: http://onlinepubs.trb.org/onlinepubs/sr/sr254.pdf 